\title{
MORFOLOGIA DA PAISAGEM E IMAGINÁRIO GEOGRÁFICO: Uma Encruzilhada Onto-Gnoseológica
}

\author{
CAIO AUGUSTO AMORIM MACIEL \\ Universidade Federal de Pernambuco
}

\section{Introdução}

Paisagem é um símbolo que necessita de permanente atualização. Como instrumento de apreensão do espaço pela geografia ela representa uma de nossas mais ricas tradições, e também mais profundas querelas. Neste debate, toma-se urgente desvendar como o imaginário da natureza é decodificado em valores simbólicos economicamente materializados, pois as práticas espaciais da humanidade não podem ser vistas como meramente racionais. Penetrar nas representações é compreender o espaço tanto através dos processos visíveis, quanto por meio dos aspectos míticos dos lugares, e a paisagem pode ser fundamental nesta conexão obrigatória entre pensamento e imagem.

Dimensão morfológica da paisagem

O universo, tal como o vemos, é urna criação, evolução e destruição incessantes de formas. (THOM, 1972)

A geografia possui uma vasta herança como discurso ordenador do mundo a partir da descrição das formas operadas pela natureza e pelo homem, buscando explicar suas conexões. A perspectiva paisagística em nossa disciplina consiste em descobrir, inventariar e diferenciar o espaço terrestre a partir, sobretudo, de seus elementos visíveis. Esta dimensão do objeto liga-se diretamente à constatação da variada feição do mundo material, qualquer que seja a interpretação subjetiva ou a sensibilidade histórica em jogo.

Como já ressaltou Odile Marcel (1994:6), a paisagem geográfica é uma configuração espacial em que as formas são suficientemente plurais para constituírem um conjunto cuja determinação interna é qualificável e descritível enquanto uma singularidade morfológica - quer se trate de espaços concretos ou do modo como eles são interiorizados mentalmente:

Antes de compreender o olhar do homem sobre o mundo que lhe acolhe e repele, antes de se tornar o território de sua exploração e intervenção, a paisagem é o fato do mundo, a sua feitura.

Neste sentido estrito, ela pode mesmo ser considerada como um dado pré-humano ${ }^{1}$, fazendo parte das possibilidades da própria natureza. É preciso não negligenciar que tal concepção somente pôde ser aventada dentro de uma nova racionalidade, qual seja, no bojo do próprio discurso científico. Considerando, em acréscimo, a consciência da humanidade e a história, a

1 Para uma sucinta discussão filosófica do tema, ver MARCEL, Odile. "Le paysage comme objet philosophique". Géographie et Cultures, 13, 1994. pp.3-22. 
paisagem sempre foi feita de singularidades culturais, de representações únicas dadas pelas perspectivas da subjetividade e das sensibilidades sociais, o que até hoje é fonte de controvérsias filosóficas importantes.

Essas perspectivas filosoficamente opostas trazem implicações diferenciadas para o estudo da morfologia do mundo visível. Há alguns pontos pacíficos: em primeiro lugar, paisagem vai muito além do real oferecido pelos fatos da natureza, embora deles faça parte, tanto quanto da cultura; em segundo lugar, a paisagem não se esgota na narração das características materiais - naturais ou não - de uma região, mesmo que se considerem as diferentes ênfases entre as escolas do pensamento no que tange à centralidade do trabalho descritivo.

Para compreender as formas que são reveladas através da observação, o geógrafo deve reunir, comparar e decifrar os padrões espaciais constatados, buscando analisar a localização dos elementos, a teia de relações que os unem e os processos que os ensejam e alteram. Desta maneira, os elementos da paisagem não são vistos como formas separadas, mas em íntimo e dinâmico inter-relacionamento. A controvérsia central neste caso é se/como a descrição detalhada, ordenada e sistemática da morfologia da paisagem conduziria concomitantemente a algum tipo de reflexão sobre a conexão entre os fenômenos e aquilo que lhes está subjacente, quer sejam processos simbólicos ou relações de causa e efeito.

Durante muito tempo se admitiu que a tarefa maior da disciplina era o exame de todos os fatores que ocorressem em interações espaciais significativas para conferir a feição singular de uma área da superfície terrestre ${ }^{2}$. As descrições e análises partiam do pressuposto de que através da aparência seria possível revelar o sentido das relações entre o homem e a natureza, as quais estruturariam o espaço. A descrição, portanto, conduziria à explicação. $\mathrm{O}$ enorme avanço do conhecimento das áreas afins impossibilitou de fato esta pretensão de síntese total (GOMES, 1997:20), apesar de que ainda compete à geografia, em grande medida, o papel de elaboração e explicação da imagem do mundo e da ordem espacial das coisas.

As técnicas de descrição regional surgiram como conseqüência da necessidade de esquadrinhar objetivamente toda a superfície da Terra, pré-requisito para a explicação da unidade do planeta. O pragmatismo da ciência da paisagem devotou interesse primordial na pintura progressiva do grande quadro das formas, sua composição, distribuição e organização efetiva no espaço. Assim, a paisagem considerada como entidade concreta foi objeto de uma ampla apreensão técnica, justaposta aos modos culturais de olhar os lugares e classificá-los numa hierarquia mundial. A objetividade deste monumental trabalho de conhecimento do mundo permaneceu, apesar de tudo, entremeada por pressupostos simbólicos do olhar fortemente calcados na cultura, incluindo as tradições científicas. A construção do olhar geográfico representa uma visão inteiramente nova e amplificada sobre o espaço em nível universal, incorporando a sensibilidade artística ocidental e a racionalidade das ciências naturais. Mas como mostra Odile Marcel (1994:17), conquanto resposta à conquista global da superfície terrestre, a objetivação do espaço pela modernidade permitiu de maneira concomitante a sua afirmação subjetiva.

A contradição entre descrever exaustivamente aquilo que é singular, por um lado, ou explicar o feitio integral do mundo, por outro, seria resolvida através das generalizações, criando conjuntos de formas espaciais gerais e uniformes a partir das regularidades constatadas nos estudos de caso. A bem da verdade, o primado da forma como pré-requisito para explicar o mundo conduziu a uma inversão indesejável de objetivos: a reificação e consequente engessamento da descrição enquanto gênero interessado em certos temas que devem ser apresentados em uma ordem préestabelecida, o que acabou por empobrecer a potência explicativa destes procedimentos técnicos. Além do mais, descobriu-se que contemplar a natureza não é uma atitude natural, biologicamente padronizada (ROGER: 1978; Berque: 1990). Admirar pressupõe dirigir o olhar e interpretar de alguma maneira o que se vê. Trata-se, portanto, de uma atitude hermenêtica, um dos caminhos que conduzem da forma ao significado.

Por isto os aspectos da forma, hoje, remetem à reciprocidade entre o sujeito e objeto na construção da paisagem como categoria de análise, quer o estudo se realize de maneira interdisciplinar, remetendo ao anseio holístico original, quer enfatize certos processos biológicos, físicos e humanos que a constituem. A inseparabilidade forma/conteúdo vai-se tomando mais

2 R. Hartshorne (1939) mostrou que a busca pela descrição das características únicas das áreas havia sido a grande nota de consenso entre o trabalho de geógrafos até aquele momento, sendo assim por ele considerada como da própria natureza da disciplina. 
explícita, superando o caráter assessório dado a uma ou outra dessas dimensões quando o destaque recai num dos pólos. Este longo movimento de redefinição do potencial elucidativo da morfologia resultou no realce da necessidade de relacionar a fisionomia com os demais aspectos da existência das coisas e objetos, como função, estrutura e processo; por outro lado, é patente o próprio questionamento do modo como são objetivadas as construções mentais, afetivas e ideológicas que interferem na formatação do ambiente vivido e dos discursos que daí emergem.

É importante reter que a geografia esteve sempre de algum modo ciente de tudo isto, mas as respostas produzidas pelo discurso acadêmico não foram minimamente consensuais, ou não conseguiram ultrapassar de uma vez por todas a barreira do inventário descritivo de tipo positivista. Duas contribuições são de suma importância para o estudo morfológico: a escola das monografias regionais na França e a geografia cultural norte-americana.

$\mathrm{O}$ organicismo presente em Vidal de la Blache, por exemplo, lutou para que o sentido da descrição fosse autenticamente explicativo, já que a natureza era considerada por ele uma totalidade que podia ser conhecida em si mesma pela observação de seu desenvolvimento; era matéria em movimento de auto-realização permanente, definida como sua própria essência. A forma reuniria matéria e finalidade em um só conjunto, o meio - domínio epistemológico da geografia. Nesta concepção, o meio é um ente concreto e pode ser objetivado pelo saber científico através do estudo de sua fisionomia, que é uma expressão da singularidade das combinações de força, e das relações de causa e efeito decorrentes da conexão entre os seus elementos constitutivos. Assim, o aspecto fisionômico daria acesso ao entendimento da essência invisível subjacente aos fenômenos visíveis, sendo a importância superior da ação humana decorrente de seu potencial de transformação do meio, bem como de sua capacidade de atribuir sentido e reconhecer as formas dessa potência adormecida na matéria. $\mathrm{O}$ corolário do pensamento morfológico lablacheano pode ser assim resumido: "As próprias formas procuram organizar-se entre si, para realizar um certo equilibrio" (apud. GOMES, 1996: 204). O primado da forma é justificado através da teleologia que conduz necessariamente da diferenciação do visível à explicação.

Um dos mais importantes saltos epistemológicas com destaque para a dimensão morfológica foi levada a cabo por Carl Ortwin Sauer. Em 1925, na sua paradigmática obra The Morphology of Landscape, ele definiu a paisagem geográfica como o conjunto das formas naturais e culturais associadas em área. Ela seria, assim, o resultado da cultura (o agente), ao longo do tempo, sobre o quadro natural (meio ou berço). A atenção central neste objeto de estudo decorre de seu cuidado em afirmar a disciplina em torno de uma seção definida da realidade, assumindo, entretanto, uma postura crítica quanto ao mecanicismo de matriz determinista dos trabalhos realizados anteriormente ou por seus contemporâneos na geografia americana.

Inspirado nos geógrafos alemães Alfred Hettner e Siegfried Passarge, Sauer vê uma persistência do interesse na corologia (conhecimento da expressão variada das diferentes partes da superfície terrestre) aceitando as abordagens de outras disciplinas desde que orientadas para as variáveis expressões espaciais de seus respectivos objetos. Se os fenômenos que compõem uma área não estão simplesmente reunidos, mas interdependentes e em associações, caberia à geografia a tarefa de descobrir tais conexões e sua ordem implícita (SAUER, 1998:175).

Para Sauer, a tarefa da geografia

é concebida como o conhecimento de um sistema crítico que envolva a fenomenologia da paisagem, de modo a captar em todo o seu significado e cor a variada cena terrestre (SAUER, 1998:22).

Tributária da posição lablacheana, esta visão relacional é, no entanto, inovadora posto que ressalta os trabalhos do homem, via cultura, como uma expressão integral e máxima do sistema da paisagem, ou cena:

Os objetos que existem juntos na paisagem existem em inter-relação. Nós afirmamos que eles constituem uma realidade como um todo que não é expressa por uma consideração das partes componentes separadamente, que a área tem forma, estrutura e função e dai posição em um sistema e que é sujeito a desenvolvimento, mudança e fim. 
A paisagem é, em essência, uma forma da Terra cujos processos de modelagem são físicos e culturais a um só tempo, possuindo uma identidade calcada em uma constituição reconhecível, limites e relações com outros lugares num contexto maior. Explica-se por esta via a relevância dada aos aspectos materiais da cultura, aos objetos e técnicas que imprimem uma marca visível no espaço, bem como a negligência com a cultura não-material.

$\mathrm{O}$ esforço analítico da geografia cultural dirige-se para a superação do excessivo hermetismo das monografias regionais de inspiração francesa, buscando recolocar em evidência o sentido da distribuição e da associação dos fenômenos e formas em área. Ele aponta um horizonte mais largo que o dos preciosismos da configuração de um espaço escolhido, pois em sua argumentação a paisagem não é mera cena, mas tipo de cena - generalização a que se chega após a observação e comparação de vários episódios individuais. Tal abordagem, pode-se afirmar, recupera o sentido da descrição numa ciência que se queria positiva:

a descrição não é de una cena individual, mas de um somatório de características gerais (SAUER, 1998: 27).

Trata-se de imprimir uma sistemática padronizada, um método à observação, elevando seu status científico, ao mesmo tempo em que se tenta uma síntese dos elementos da forma. Apesar de Sauer reconhecer que as monografias regionais descobriram na paisagem cultural a expressão máxima da área orgânica, ele demarcou bem a discordância com a sua seleção impressionista dos fenômenos e a excessiva liberdade artística. A padronização dos dados a observar constituiu seu trunfo metodológico contra o livre arbítrio e as idiossincrasias que caracterizavam a geografia humana até então.

Tornou-se lugar comum afirmar que o rigor da descrição não salvou a geografia humana dum empirismo renitente, pois a acachapante proeminência da forma trouxe poucas garantias à legitimidade da explicação. As tipologias morfológicas foram seu resultado mais "científico", o que não escapou à polêmica de que uma ciência não se faz pela simples catalogação de padrões. É patente hoje que a preocupação com o inventário do concreto através das exaustivas descrições das formas da superfície terrestre ofuscou as etapas subseqüentes do pensamento, o que na opinião mais ou menos geral da comunidade científica não revelou satisfatoriamente o complexo dinamismo do espaço geográfico.

Há outras heranças contraditórias no seio deste debate. Desde muito cedo o interesse por desenvolver a análise da morfologia da paisagem foi influenciado pelos instrumentos conceituais existentes no plano biológico, daí esta tradição ter estabelecido uma tenaz influência na construção do objeto geográfico. O relacionamento de forma com função, processo e estrutura, acompanhou e dialogou com os subsídios oferecidos pela biologia, principalmente pela ecologia, como nos trabalhos de Carl Troll (1950/1997), Hans Bobek e Josef Schmithüsen (1949/1998) e G. Bertrand (1978). Nestas abordagens a apreensão da morfologia em unidades ao mesmo tempo espaciais e ecológicas conferiu uma maior atenção não às formas/estruturas propriamente ditas, mas aos processos que as engendram. Esforço em que permanece patente a tarefa histórica da geografia, ou seja, unir as duas facetas da noção de paisagem - humana e natural - insistindo mais uma vez sobre o tema da integração e modificação do meio pelo homem, a despeito de não se chegar a uma teoria geral da paisagem (BERDOULAY \& PHIPPS, 1985:10).

No que se pode chamar de ecologia da paisagem, em grande parte também herdeira de Siegfried Passarge, o objeto da geografia é o espaço lito-bio-atmosférico, porém a ênfase recai não na descrição do visível, e sim nas relações íntimas entre os fenômenos espaciais em três dimensões: físicas, biológicas e noóticas ${ }^{3}$. Tal abordagem sistêmica inova ao centrar esforços no relacional, ao invés de apenas catalogar configurações territoriais. Daí, a maior contribuição para o estudo da morfologia prende-se ao objetivo de descobrir uma ordem dentro da multiplicidade, almejando decompô-la para explicar as relações que produzem a paisagem. Este caminho mostrou a riqueza da interface com a ecologia e a biogeografia, culminando com grande caudal

3 O interesse da ecologia pelo conceito de paisagem é muito fértil, desde que ele se reporta de alguma maneira ao ambiente e aos processos propriamente ecológicos que propiciam a evolução das estruturas espaciais. A geografia, a seu turno, se interessa pelas diferentes maneiras de percepção ambiental dos povos e indivíduos, além de incorporar os fenômenos naturais enquanto produtores de uma dada configuração da superfície terrestre. A ecologia da paisagem é, portanto, um área transdisciplinar do saber 
de pesquisas contemporâneas em ecologia da paisagem.

De que maneira tais abordagens originaram novos enfoques epistemológicos e proposições para a dimensão morfológica? Comentando o interesse da ecologia pelo conceito de paisagem, Berdoulay e Phipps (1985:12) advertem para a inexistência de um consenso no seu interior, apesar de uma tradição significativa dos aportes da biogeografia. Para estes geógrafos, o mais importante nos trabalhos sobre paisagem numa perspectiva sistêmica é que houve uma preocupação em refletir em que medida as abordagens ecológica e semiótica (relação entre forma e sentido, significado e significante) podem ser convergentes, recolocando o homem como razão de ser da própria noção de paisagem. No meu entender, a visão geográfica holística (ou ecológico-semiótica) procura superar a redução da paisagem ao sentido naturalista de meio, como frequentemente se percebe na biologia.

O empenho de Berdoulay e Phipps por uma teoria geral da paisagem sugere a busca de quadros teóricos que permitam a integração, ao menos parcial, das abordagens ecológicas e semiológicas na geografia. Os autores propõem que o estudo da paisagem se remeta aos sistemas organizados e à teoria da organização, a qual pode se apoiar por sua vez em outras proposições, como a teoria da informação, a termodinâmica e a teoria das catástrofes. $\mathrm{O}$ apelo à forma como elemento central da análise nesta última toma mister que nos reportemos ao pensamento de René Thom (1972). Ele explica que catástrofe tem a ver sempre com uma mudança abrupta de regime, seja no mundo material, biológico ou mesmo no campo das idéias. Uma população de ratos que cresça lenta e progressivamente chegará a um limiar em que seu comportamento mudará bruscamente, em decorrência, por exemplo, da falta de alimentos. De maneira análoga, a existência dos objetos é percebida por nossa visão através de seus contornos ou arestas, que são "linhas de catástrofe", de mudança abrupta de um plano a outro.

Em casos complexos, como a feição de uma paisagem, a catástrofe é mais difícil de perceber. Não obstante, onde quer que haja forma, há uma catástrofe (e sua dinâmica subjacente). No dizer de Thom, o contorno é a forma do ser. Daí, os conceitos também podem ser vistos como formas. Eles possuem "bordas" que os separam dos outros seres do universo cognitivo e vocabular. O que seria o contorno do conceito? Simplesmente a sua definição, pois como ensina o autor a significação de uma forma se manifesta apenas pelas catástrofes (arestas, contornos) que a criam ou destroem. Assim, compreende-se o axioma tão venerado pelos lingüistas formais:

$$
\text { o sentido de uma palavra nada mais é do que o uso dessa palavra (THOM, 1972:321). }
$$

Cada uma das formas da paisagem, bem como cada modo de concebê-la, seria uma catástrofe e o seu conjunto seria um sistema de catástrofes. A pesquisa das dinâmicas implícitas na formação dos elementos e representações da paisagem se faz, na prática, pela análise das descontinuidades fenomenológicas (físicas, humanas, conceituais) presentes. Por isso, o trabalho do geógrafo interessado na paisagem pode ganhar, a partir desta teoria, uma conotação semiológica, como querem os autores supracitados, ou hermenêutica, de acordo com as correntes interessadas na interpretação histórica (ou gênese) dos fenômenos.

Finalmente, e talvez o mais importante: a perspectiva de Thom é um caminho promissor para a superação da dicotomia forma/conteúdo além da simples retórica. Tenho notícia do esforço de geógrafos franceses que se referenciam explicitamente em René Thom e seus seguidores. Na coletânea "Paysage et Système — de l'organization écologique à l'organization visuelle" (BERDOULAY \& PHIPPS, 1985) os organizadores reuniram trabalhos que abordam a paisagem como um sistema de elementos em interação, evitando tanto a dispersão de uma multiplicidade de enfoques isolados quanto o aprisionamento em visões setoriais deste campo de pesquisa. Foi privilegiada a consideração das ligações epistemológicas que podem existir entre a análise das estruturas espaciais e ecológicas e a análise da paisagem percebida. A ênfase recaiu sobre as estruturas espaciais, formas perceptíveis produzidas pelo funcionamento ecológico, antes que sobre os processos produtores destas formas.

O enfoque ecológico considera o "Todo", via-a-vis de suas partes, sendo que esse todo não pode ser explicado pelo mero arranjo de seus componentes. O holismo que o embasa parte do pressuposto da evolução emergente, ou seja, de que existem fatos novos na natureza, e de que "Todos" inteiramente novos são efetivamente produzidos por uma força criativa do universo. À medida que novos componentes são reunidos para formar unidades funcionais maiores, novas 
propriedades emergem - propriedades estas que não estavam presentes quando os componentes existiam isolados. Os geógrafos interessados na compreensão/explicação da paisagem foram atraídos por esta abordagem porque ela abriga a idéia de que os componentes vivos (organismos, inclusive o homem), como também os componentes não-vivos (o meio físico) funcionam juntos, como um todo, de acordo com leis físico-químicas e biológicas bem definidas, o que está na base do conceito de ecossistema. Re-oxigena-se, assim, o antigo corolário lablacheano de que a geografia estuda a constante emergência do novo na superfície terrestre.

Os autores citados insistem nos dois lados da realidade paisagística que abarcam as abordagens ecológica e semiótica, propondo uma ciência da paisagem como tradução holística de espaço vivido: um approach integrado, levando em conta os componentes naturais e humanos. A definição subjacente de paisagem é a de um conjunto de signos produzidos pelo funcionamento ecológico os quais seriam percebidos e carregados de significações pelo observador, e interpretados por "tradutores" de quadros sócio-culturais. A lógica ecológica e a lógica do significado se encontrariam na paisagem, lugar semiótico. Assim, estruturas objetivas conduziriam a um modelo de organização subjacente a todas as paisagens visíveis, fornecendo os signos/informações decodificados pelo observador (BERDOULAY \& PHIPPS, 1985:passin).

Nesta abordagem, há que se considerar uma paisagem visível, concreta (conjunto de significantes possíveis) e a determinação da leitura levada a cabo por um certo olhar (significados). A análise semiótica e ecológica da paisagem realiza uma das possíveis leituras de Thom, privilegiando o mundo natural do corpo e da coisa num viés empirista que remete ao positivismo lógico. Porém, é preciso que se demarque neste momento que, em forte contraste com esse tipo de análise lógica da significação, existe a corrente hermenêutica, cujo método de estudo é eminentemente histórico, como será visto no próximo item.

\section{Força imaginal e dimensão simbólica da paisagem}

O símbolo jamais é explicado de uma vez por todas, mas deve ser sempre decifrado de novo; assim uma partitura musical nunca é decifrada de uma vez por todas, mas exige uma execução sempre nova. (CORBIN, apud. DURAND, 1988:18)

Espero haver deixado claro no item anterior que seria obsoleto discutir o conceito de morfologia da paisagem sem remetê-lo de maneira mais ou menos enfática à dimensão do significado, como foi tentado, aliás, em diferentes caminhos discutidos pelas escolas do pensamento geográfico. Entretanto, não há dúvidas de que a perspectiva simbólica vem adquirindo uma crescente importância no discurso acadêmico, contribuindo para revitalizar o conceito de paisagem ao se apreciarem criticamente os aportes tradicionais e/ou mediante o aprimoramento de seu embasamento teórico. A inversão de sentidos assenta-se no reconhecimento do papel central do espírito humano: a paisagem pode ser uma realidade interpretada pelos habitantes e subjetivamente dotada de sentidos por eles na medida em que forma um mundo coerente para as suas ações cotidianas.

É mister a afirmação de que equiparar as dimensões da forma e do sentido mostrou-se esforço legítimo somente em função da renitência com que a poiesis, ou força criativa da humanidade, resistiu aos ataques do pragmatismo na ciência. A geografia humana não poderia manter-se como um ramo das ciências naturais. Como disse Denis Cosgrove (1984:17), todo o esforço visando tornar científico o conceito de paisagem não foi suficiente para separá-lo totalmente de suas raízes estéticas e subjetivas; toda paisagem é simbólica, é também aquilo que se imagina e que recebe diferentes valorações e sentidos culturais.

Focar a cultura como um conjunto de significados e atividades plenas de sentido remete inevitavelmente à ação humana, ao seu poder de simbolização e à significância reprodutiva do ritual (GREGORY \& SMITH, 1986). A renovação da geografia cultural pelas humanidades, tomando para si tais questões, apresenta grande potencialidade para reparar o peso excessivo geralmente dado à estrutura econômica na explicação tradicional em geografia humana. A retomada do humanismo na geografia insiste em pontos básicos:

os lugares não têm somente uma forma e uma cor, uma racionalidade funcional $e$ 
econômica. Eles estão carregados de sentido para aqueles que os habitam ou que os freqüentam (CLAVAL, 1999: 55).

A emergência do sentido abre um leque vastíssimo à geografia da paisagem, representando a possibilidade de ultrapassar os muros da razão e a iconoclastia redutora da ciência positiva. Falei anteriormente da tentativa de interpretação racionalista levada a cabo pela semiótica ecológica; neste momento lançarei um olhar mais acurado numa perspectiva contra-racionalista que toma para si a tarefa de instaurar uma hermenêutica restauradora da imagem, dos simbolismos e do imaginário como elementos válidos do discurso científico.

Uma abordagem que privilegie o papel central e ativo da sabedoria, consciência, imaginação e criatividade humanas é uma abertura para compreender os sentidos, valores e significados dos eventos da vida, no dizer de Buttimer (1979). Mas não se trata de tarefa das mais simples ou isentas de controvérsias. A tensão básica que alimenta as correntes humanistas advém das ambigüidades com que a paisagem se revestiu ao longo de sua construção como um objeto do saber, ou seja, a permanente oscilação do conceito entre o individual e o social, bem como entre o objetivo e o subjetivo. Tais conotações geram problemas para os que querem uma definição pura, científica e precisa - denotando a atualidade dos debates sobre a incorporação da subjetividade e das paixões humanas às reflexões acadêmicas. Entretanto, para Cosgrove (1984:15), é justamente devido à ambigüidade de buscar compreender o espaço terrestre tanto como sujeito quanto como objeto da ação humana que a geografia pode ser melhor alinhada aos objetivos e métodos das humanidades - e mais precisamente aos seus modos de compreensão hermenêuticos.

Tanto quanto a abordagem semiológica, a hermenêutica aceita que o conceito de paisagem comporta necessariamente um componente visual (morfológico), e assim sendo se deve considerar a questão dos significados atribuídos àquilo que se percebe. Como afirmam Berdoulay e Phipps (1985), o observador separa o visto do visivel, sendo que para a semiologia ecológica esta operação só pode ser compreendida através do suporte natural da paisagem enquanto nível de organização semiótica, o que finda por reduzir a própria amplitude da interpretação. E por esta razão que o método semiológico revela-se mais profícuo em situações onde o componente biológico da paisagem é muito marcado. Para Mondada e Racine (1995:247) o que está em questão no approach sistêmico dos autores acima é a apreensão da paisagem em sua materialidade, buscando-se os fundamentos ecológicos de sua semiótica e o lugar de emergência de seu sentido. O que se almeja, em última instância, é uma leitura do "texto" paisagístico que explicite as condições de construção dos objetos geográficos.

A hermenêutica, por seu turno, privilegia a história e a cultura em seu sentido mais amplo, instrumentalizando reflexões orientadas pelo e para o humanismo. O texto aqui é mais carregado de sentidos, a leitura podendo ser dirigida por tradutores artísticos, antropológicos e históricos. Neste sentido, junta-se ao cabedal de críticas mais gerais e profundas à pretensa objetividade do saber. Contudo, aceitar as ambigüidades acima aludidas não significa abandonar o conceito em estudo, mas observar cuidadosamente os contextos em que se originaram seus significados culturais. Em poucas palavras: o foco geral dessas interpretações congrega atributos humanos para além da razão. Neste sentido, falar de significado não se restringe à consideração de signos, modelos e padrões de relação funcional entre os símbolos e os sujeitos da observação, apesar de também incluir isto; antes, porém, o significado em seu sentido mais contundente remete à consideração do imaginário geográfico e do plano afetivo como uma força criativa da realidade. Michel Maffesoli (1992) usa analogamente a expressão força imaginal em relação à política, e na geografia vários autores chamam a atenção para um papel semelhante desempenhado pelo deleite estético (RELPH, 1987; APPLETON, 1986) ou pelos laços cotidianos das pessoas com os lugares (TUAN, 1974; LOWENTHAL,1986). Já Denis Cosgrove, na obra citada acima, sublinha o sentido ideológico do termo, enquanto uma imagem calcada numa consciência falseada da realidade a serviço da dominação de classes.

Vista em perspectiva pelo humanismo em geografia, a paisagem recolocaria a preocupação com a construção social do espaço, ao invés de privilegiar o "confinamento espacial de pessoas e povos" (GREGORY \& SMITH, 1986:208). Como produto social, incorporaria à memória pessoal e histórica uma materialidade real, fundadora das representações. Para a hermenêutica em especial o imaginário é nuclear, pois a incorporação do concreto se faz de forma indireta, a partir de códigos e símbolos instituídos coletivamente. Por exemplo, no imaginário geográfico de que 
fala Castro $(1997 ; 2000)$ a natureza não pode ser vista como um dado independente da representação social; quer dizer, em sua cristalização enquanto paisagem ela é percebida, interpretada e mediatizada pelas representações ${ }^{4}$. A terra é um registro simbólico tanto quanto uma fonte de recursos, daí possuir as marcas da existência humana como se fosse um texto à espera de tradução. O caráter duplo é resultado da construção social da realidade de que tratam $P$. Berger e T. Luckmann (1988) em sua sociologia do conhecimento. A paisagem é uma realidade objetiva, mas que somente adquire vida no pensamento e nas ações daqueles que a habitam. A vida da paisagem ao nível do pensamento brota da relação entre o "eu" e sua "circunstância", neste caso tudo que foi dado previamente à existência e que se costuma denominar de natureza. Pois bem, o eu interage com os seus semelhantes (intersubjetividade), transforma e interpreta a natureza, donde resulta a idéia de mundo. Nesta concepção da existência a paisagem pode ser vista basicamente como uma circunstância interpretada.

A natureza sempre esteve presente no imaginário social da humanidade, o que significa dizer que há de fato um imaginário geográfico concorrendo para a elaboração das diversas visões de mundo, incluindo aquelas propriamente paisagísticas:

Portanto, se a paisagem remete necessariamente à natureza e à representação, ambas remetem ao problema do imaginário em função da mediação simbólica que assume a representação da natureza para os mais diferentes grupos sociais. (CASTRO, 2000:6).

A paisagem tem uma dimensão espacial - o "fato do mundo", como já citado por Marcel - e uma dimensão temporal decorrente das suas diversas interpretações ao longo da história. Aceitando com Berger e Luckmann (1988:77) que "a expressividade humana é capaz de objetivações" (trabalho, ação) percebe-se que a vida em sociedade consiste justamente na trama dessas objetivações, das quais se destaca a significação como a mais importante - a produção humana de signos e sentidos. Todo um acervo social é reunido em campos semânticos ou formas de significação lingüisticamente circunscritas.

$\mathrm{O}$ estoque social de conhecimento representa o mundo vivido cotidianamente pelos grupos humanos, e este dia-a-dia integrado é um ingrediente fundamental da paisagem. A arte, a religião e o imaginário em geral são produtores deste campo de significação do mundo. É daqui que a compreensão geográfica deve insistir "sobre o sentido dos lugares, sobre a importância do vivido, sobre o peso das representações religiosas" tornando indispensável um estudo aprofundado das realidades culturais (CLAVAL, 1999:53).

A relativização da racionalidade não significa, contudo, uma volta aos delírios e às arbitrariedades românticas. Castro ressalta que antes de qualificar em separado um imaginário geográfico, o problema da paisagem impõe a tarefa de interpretar a geografia contida no imaginário social (e expressa no próprio discurso geográfico) como um dos caminhos para compreender o papel que as representações do meio desempenham nas práticas espaciais e na organização do espaço. Pressupondo que todo imaginário social é também imaginário geográfico, ela afirma que não há como dissociá-los, porque embora fruto de um atributo humano, a imaginação é alimentada pelos atributos espaciais.

Há, portanto, na gênese das representações humanas das formas concretas uma força imaginal subjacente. Ora, aqui está a "mágica" da paisagem! Quando examina uma dada configuração territorial, a geografia busca identificar as singularidades do contorno visível desta fisionomia. Tais singularidades são captadas pela nossa mente a partir das projeções desses contornos pelos sentidos, que apenas refletem parcialmente aquilo que se passa no Ser espaço, onde subjaz verdadeiramente a dinâmica em parte inalcançável do sistema. Assim, as coisas percebidas constituem, no fundo, reflexos de coisas não percebidas; isto é, há sempre a epifania de um segredo quando se interpreta a paisagem. A hermenêutica, enquanto arte e ciência da interpretação - assumindo assim papel de destaque no pólo epistemológico segundo uma postura que se contrapõe ao reducionismo da lógica formal - seria justamente a maieutica que auxiliaria o geógrafo na parturição dessa epifania.

Por esta razão a leitura semio-ecológica da paisagem a partir de R. Thom não é a única

4 Segundo CASTRO (2000:5), representação pode ser minimamente definida como "uma estrutura cognitiva mental relativamente geral e abstrata, a partir da qual pode-se falar em um modelo, internalizado pelos individuos de uma sociedade, que permite conceitualizar o real". 
possibilidade de aplicação da sua teoria. Aliás, em artigo mais recente ele afirma textualmente que a teoria das catástrofes, sob sua forma mais pura, é de qualquer maneira uma hermenêutica (THOM, 1991:31). Ao analisar morfogeneticamente uma fenomenologia qualquer há um ponto em que o cientista vê o seu processo tomar uma figura, surgir como uma forma que precisa ser interpretada, remontando-se à sua história ou gênese.

A pretensão do método hermenêutico é compreender um objeto - no caso em estudo, a paisagem - de uma maneira mais aguda do que poderiam fazê-lo os que vivem nela, posto que o recurso à história possibilitaria penetrar fundo no sentido da vida. A liberação do compreender histórico daria acesso a um modo de entendimento originário, quer dizer, a partir da gênese dos fenômenos. A ressalva a ser feita é quanto ao fato de que a própria história deve ser tomada como uma reconstituição intencional do passado e assim sendo só pode ser vista como narrativa (GOMES, 1997:31). Uma análise objetiva dos sentidos históricos não pode deixar de considerar as re-invenções da tradição efetuadas no presente.

De qualquer maneira, o foco é colocado não sobre o objeto mesmo, mas sobre as suas relações com modos de pensar. Para a teoria da construção social da realidade a linguagem é o grande depósito de sedimentações coletivas de sentido. Isto conduz, por sua vez, aos estudos lingüísticos, através da necessidade de reconhecer a transmissão das tradições mediante a linguagem. Também o papel da arte e da religião é ressaltado para o entendimento dos valores e significações construídos culturalmente por um grupo social. Acredito que se devem especificar os estudos das mitologias e das metáforas espaciais como pontos-chave para a geografia preocupada com as representações sociais da realidade.

De um modo mais ou menos operativo o moderno humanismo em geografia lança mão do método de interpretação hermenêutica, mas as diferenças teóricas não são negligenciáveis. No interior deste grande bloco do pensamento as divergências revelam a efervescência do tema. Em sua revisão do resgate humanístico da paisagem, um dos expoentes da nova geografia cultural anglo-saxônica, o marxista Denis Cosgrove (1984; 1998), busca demarcar uma posição original sintetizada pela introdução do materialismo histórico como ferramenta metodológica. Ele critica, assim, a chamada "geografia da percepção" de Yi-Fu Tuan ou de David Lowenthal por não haver se calcado em uma forma adequada de explicação social ou histórica, preferindo o tratamento da psicologia para o indivíduo, tema que seria de interesse geográfico menor ${ }^{5}$.

Assim, o sensível comporta leituras por vezes antagônicas. Há vários aportes relevantes sobre a dimensão do significado na nova geografia cultural, entre os quais a fenomenologia de Berque $(1994 ; 1995)$ e a aludida geografia crítica cultural de Cosgrove; porém, seria enfadonho proceder um apanhado completo de todos os temas e autores, correndo-se o risco, ademais, de cometer omissões. Como esses dois pensadores já são mais conhecidos, chamo atenção aqui para a originalíssima contribuição de Michel Roux, através da sua geografia do imaginário. O trabalho Geographie et Complexité - Les Espaces de la Nostagie (ROUX, 1999) é uma tentativa de aplicação empírica da problemática do imaginário espacial. Partindo de dois exemplos representativos da constituição de uma geografia mítica na França - as paisagens arquetípicas do deserto e do mar - ele mostra como até mesmo os conteúdos e ilustrações dos livros didáticos que se pretendem mais utilitários, racionais e objetivos estão carregados de emoção, afetividade ou ideologia.

Usando análise fatorial com suprema ironia quanto às "exigências do determinismo funcionalista", o autor nos conduz a conclusões surpreendentes: o Saara dos Regs, coberto em $75 \%$ por seixos e cascalhos, dá lugar, nesta geografia mítica, à onipresença das vastas extensões arenosas que ele chamou de dunas metonímicas. Da mesma forma, verifica analogias nas estruturas de representação do oceano e da costa francesa, que são uniformizados pelo azul indiviso dos mapas. Este estudo de caso dá fôlego a interessantes correlações entre imaginário e realidade. As evidências desconcertantes do poder do imaginário conduzem a geografia a pautar suas preocupações absorvendo o efeito daqueles comportamentos não-racionais que induziriam formas espaciais concretas. Se a imaginação incide sobre as representações mais rigorosas dos

5 O criticismo humanista permite apenas um consenso: a refutação do modelo clássico da ciência positiva. Para Gomes (1996:325337 ) isto explica os caminhos, por vezes irreconciliáveis, que tomaram as perspectivas incorporadoras do subjetivismo e mesmo do irracionalismo. A despeito das divergências, Cosgrove (1984:15) reconhece a importância de trabalhos como os de Lowenthal (1986) para a demonstração das profundas diferenças de perspectiva entre o observador externo e o insider da paisagem, resultando em que se apliquem significados e valores muito diferentes para um mesmo conjunto de formas. 
manuais de estudo, como ele demonstrou, é de se esperar que alimente comportamentos econômicos diferentes e contraditórios na origem de variadas ocorrências espaciais. Verifica-se um paralelismo com a paisagem-ideologia de Y. Lacoste (1977) ou D. Cosgrove (1986), aqui, entretanto, com um sentido ampliado para fora dos marcos do falseamento maquiavélico do significado.

Para Roux o pensamento mítico afina-se prioritariamente com o paradigma da complexidade proposto por Edgar Morin, onde o imaginário não empobrece ou aniquila o olhar sobre o mundo, muito menos o deforma, porque constitui uma totalidade que cria o sentido e a própria existência, resolvendo as tensões entre individualidade e coletividade. Tal síntese é facilmente encontrada nas sociedades tradicionais, onde o espaço próximo e cotidiano era investido de valores que construíam o indivíduo. $\mathrm{O}$ caso da racionalidade cotidiana moderna, com seu excesso de regras e padronização, é que pode ser visto como deformante, afirma Roux. Daí a gênese e o papel da nostalgia e do retorno às origens via contato com espaços "selvagens" em expedições iniciáticas. Esta ideologia lato sensu está nos manuais de ensino da geografia, nas propagandas de produtos voltados para a juventude, nos roteiros turísticos, nos esportes ditos "radicais" e até nos programas de governo.

Como e porque os homens se reportam nostalgicamente a espaços míticos, elegendo algumas imagens à condição de metáforas e metonímias que ordenam o mundo? $\mathrm{O}$ autor afirma que isto é uma maneira de reencontrar o equilíbrio telúrico que a modernidade técnica e os valores do progresso romperam. As ligações do homem ao espaço não estariam de todo subordinadas à realidade sócio-econômica e política, mas seriam uma "função existencial da individuação", a qual permite aos indivíduos se diferenciarem e ao mesmo tempo se integrarem ao coletivo - uma heterotopia, no dizer da nova geografia cultural. A nostalgia decorre de que os indivíduos foram oprimidos pelo avanço sem precedentes da máquina de normatização social, trocando os vínculos místicos com seus lugares de origem pelos espaços urbanos super-controlados. Aqui não interessa tanto saber as origens dessa saudade, mas sim como a valorização simbólica de determinados espaços possui repercussão fundamental nas práticas espaciais.

Uma das especulações mais frutíferas de Roux é a que considera a metáfora como rationale da imaginação, sendo a capacidade de metaforização do homem uma prova do caráter arbitrário da separação entre imaginação e pensamento racional. A "retroação homem-espaço" é a maneira pela qual as pessoas projetam dialeticamente seus sentimentos sobre a natureza, identificando correlações entre os aspectos materiais e suas pulsões interiores. Coaduna-se esta visão com a existência dum imaginário geográfico na origem das representações espaciais, como as paisagens.

Deste modo, não é o deserto que produz o asceta, mas são as pessoas que ali se refugiam voluntariamente que conferem um sentido diferente àquele espaço, atribuem-lhe valores (os quais diferem das conotações de nativos, colonizadores etc):

a imaginação é submissa a um processo intelectual interativo, aquele da metáfora, sem que esse procedimento seja consciente. Os homens transfiguram as areias $e$ as areias transfiguram o homem (ROUX, 1999: 46).

A busca de valores e sentidos identificados com a imagem metafórica das areias móveis transcende historicamente a imutabilidade evocada pelas pedras, a despeito do predomínio destas na paisagem do deserto.

\section{Considerações finais}

Paisagem permanece ao longo do tempo "um conceito-chave da Geografia" (CORREA \& ROSENDAHL, 1998:8), a despeito dos mais antagônicos ângulos adotados por diferentes tradições e correntes epistemológicas. Contudo, uma clivagem filosófica de fundo conserva-se fundamental até os dias de hoje: de um lado defende-se a necessidade de descrição das conformações naturais e culturais do espaço; de outro define-se a paisagem eminentemente como representação subjetiva do olhar. Longe de conduzir a um consenso, esta encruzilhada é o nó górdio de toda geografia que admite ontologicamente o conceito de paisagem. Como destaca 
Odile Marcel (1994:5), construir a unidade deste objeto na complexidade integrada de uma coerência intelectual é um desafio para o espírito.

Analogamente ao que Gomes (1996) mostra para o conjunto da disciplina, o conceito-chave de paisagem estaria sempre na pauta por expressar um campo de controvérsias próprias da dualidade do pensamento moderno, transparecendo a atualização das querelas entre explicação e compreensão, ou entre análise da base material versus interpretação simbólica. Ela é instrumento e intuição. Se a geografia é uma moderna cosmovisão, paisagens são os modos mais eloquentes de compor e decompor imagens através do discurso científico culturalmente centrado.

Do modo mais amplo possível, a paisagem pode ser compreendida como um trabalho discursivo de ordenamento da imagem do mundo a partir do ambiente próximo, concreto e apreensível pelos sentidos humanos, mediante estruturas mentais correntes no universo cultural de cada época e de cada povo. É a unicidade de nossa existência no mundo da materialidade física transformando-se em manifestações simbólicas que não se reduzem umas às outras. Apesar de representação, liga-se de modo contundente às formas objetivas da natureza. Esta via de conceber o espaço seria constantemente re-elaborada pelas mudanças ocorridas na sociedade, sobretudo aquelas referentes às técnicas e à comunicação. Dessa maneira, possuiria tanto uma dimensão palpável quanto um componente de imaginação, todavia inextricavelmente correlacionados. Graças à arte, à história, aos marcos discursivos de cada cultura e às diversas elaborações teóricas a seu respeito, o senso paisagístico da humanidade não cessa de se tornar mais geral, aguçado e vivo. A geografia precisa continuar atenta a este dinamismo e parece ter chegado a hora de nos debruçarmos com maior atenção sobre as ciências do imaginário.

Resumo: A experiência que os homens têm da natureza e do espaço, bem como a maneira pela qual eles os modelam de acordo com suas necessidades e desejos é cada vez mais mediada por um imaginário geográfico advindo da inundação de imagens na televisão, rede de computadores, viagens turísticas etc. Este artigo visa levantar um questionamento geral: como trabalhar empiricamente o simbólico de modo a enriquecer a análise geográfica da sociedade? Neste contexto, há um conceito-chave que necessita de permanente releitura, pois se a natureza do Espaço é ontologicamente o investimento último da geografia, sua apreensão via Paisagem é uma de nossas mais ricas tradições, e também mais profundas querelas. As reflexões aqui iniciadas levantam a possibilidade de chegarmos ao entendimento do concreto mediante a inclusão do Imaginário como processo fundamental de compreensão dos fenômenos materiais. Tal abordagem só é possível no contexto de uma hermenêutica re-instauradora do mito, onde trabalhar o simbólico não signifique o caminho oposto de abandonar o racional, mas sim de ampliar as possibilidades de enquadramento dos domínios explicativos da base material contemplando sua indelével transcendência evocativa.

Palavras-chaves: Paisagem, morfologia, hermenêutica, imaginário geográfico

Abstract: LANDSCAPE MORPHOLOGY AND GEOGRAPHIC IMAGERY: AN ONTO-GNOSEOLOGIC CROSSING. Man's experience of nature and space, together with the way he models them according to his necessities and desires all seems to be more and more mediated by a geographic imagery that has its roots in an overflow of pictures from television, computer networks. tourism, etc. This article aims at posing a general question: how best to work empirically on the symbolic, in order to enrich the geographical analysis of society? In this context there is a key concept that must be permanently revised, for if the nature of Space is geographys ultimate investment, its apprehension via the Landscape comes to be one of our richest traditions, as well as one of our most profound disputes. The reflections here presented raise the possibility of reaching an understanding of the concrete by means of the inclusion of the Imaginaire as the fundamental process in the understanding of material phenomena. Such an approach is only feasible in the context of a hermeneutics that restores the myth, where working on the symbolic does not mean treading on a path that leads away from rationality, and where the possibilities of framing the phenomena of the material basis according to the model of scientific explanation are enhanced.

Keywords: landscape, morphology, hermeneutics, geographical imaginaire

\section{Bibliografia:}

APPLETON, J. (1986): The role of the arts in landscape research. In: PENNING-ROWSELL, E., LOWENTAL, D. (orgs.) Landscape meanings and values. London: Unwin Hyman, p. 2647.

BERDOULAY, V., PHIPPS, M. (1985): Paysage, système, organization. In: BERDOULAY, V. \& PHIPPS, M.(orgs.). Paysage et Système: de l'organization écologique à l'organization visuelle. Éditions de l'Université d'Ottawa, p.9-19.

BERGER, P.L., LUCKMANN, T. (1988): A construção social da realidade. Petrópolis, Vozes. 
BERQUE, A. (1990): Mediance — de milieux en paysages. Montpellier: Reclus.

CONAN, M. et. al. (1994): Cinq propositions pour une théorie du paysage.

Seyssel: Champ Vallon.

(1995): Espace, milieu, paysage, environnement. In: BAILLY, A., FERRAS, R., PUMAIN, D. Encyclopédie de Géographie. Paris: Economica, p.349-367.

BERTAND, G. (1978): Le Paysage entre la nature et la société. Revue géographique des Pyrénées et da Sud-Ouest, 49, (2), 239-258.

BOBEK, H., SCHMITHÜSEN, J. (1998[1949]): A paisagem e o sistema lógico da geografia. In:

CORR A, R.L., ROSENDAHL, Z. (orgs.) Paisagem, tempo e cultura. Rio de Janeiro: EdUERJ, p.75-83.

BUTTIMER, A. (1979): Le temps, l'espace et le monde vécu. L'Espace Géographique, n 4, p. 243-254.

CASTRO, I. (1997): Imaginário político e território: natureza, regionalismo e representação. In: CASTRO, GOMES e CORR A. Explorações Geográficas: percursos no fim do século. Rio de Janeiro: Bertrand Brasil, pp. 155 - 196.

(2000): Paisagem e turismo: de estética, nostalgia e política. Rio de Janeiro: LAGET/UFRJ, (inédito-fotocópia).

CLAVAL, P. (1997): As abordagens da geografia cultural. In: CASTRO et al.(org.). Explorações Geográficas - percursos no fim do século. Rio de Janeiro: Bertrand Brasil, p. 89-117.

CORREA, R.L., ROSENDAHL, Z. (orgs.). (1998): Paisagem, tempo e cultura. Rio de Janeiro: EdUERJ.

COSGROVE, D. E. (1984): Social formation and symbolic landscape. London: Croom Helm.

(1998): A geografia está em toda parte: cultura e simbolismo nas paisagens humanas. In: CORR A, R.L., ROSENDAHL, Z. (orgs.) Paisagem, tempo e cultura. Rio de Janeiro: EdUERJ, p. 92-123.

DURAND, G. (1988): A imaginação simbólica. São Paulo: Cultrix.

GOMES, P.C.C. (1996): Geografia e modernidade. Rio de Janeiro: Bertrand Brasil.

(1997): Geografia fin-de-siècle: o discurso sobre a ordem espacial do mundo e o fim das ilusões. In: CASTRO, I.E; GOMES, P.C.C; CORR A, R.L. (orgs.). Explorações Geográficas. Percursos no fim do século. Rio de Janeiro: Bertrand. pp.13-42.

GREGORY, D., SMITH, D. M. (orgs.). (1986): The Dictionary of Human Geography. London: Blackwell Reference, $2^{\mathrm{a}}$ ed.

HARTSHORNE, R. (1939): The Nature of Geography. University of Minnesota Press.

LACOSTE, Y. (1977): A quoi sert le paysage? Qu'est-ce un beau paysage? Hérodote, n. 7,jul.set., p.3-41.

LOWENTHAL, D.( 1986): Introduction. In: PENNING-ROWSELL, E., LOWENTAL, D. (orgs.) Landscape meanings and values. London: Unwin Hyman, p. 1-2.

MAFFESOLI, M. (1992): La transfiguration du politique. Paris: Grasset.

MARCEL, O. (1994): Le paysage comme objet philosophique. Géographie et Cultures, n. 13, p. 3-34.

MONDADA, L., RACINE, J-B. (1995): Géographie et semio-linguistique. In: BAILLY, A., FERRAS, R., PUMAIN, D. Encyclopédie de Géographie. Paris: Economica, p239-254.

RELPH, E. (1987): The Modern Urban Landscape. Baltimore: John Hopkins University Press.

ROGER, A. (1978): Nus et paysages. Essais sur les fonctions de l'art. Paris: Aubier.

ROUX, M. (1999): Géographie et Complexité — Les espaces de la nostalgie. Paris: L' Harmattan.

SAUER, C.O. (1925/1998): A morfologia da paisagem. In: CORR A, R.L., ROSENDAHL, Z. (orgs.) Paisagem, tempo e cultura. Rio de Janeiro: EdUERJ, p. 12-74.

THOM, R. (1972): Structural stability and morphogenesis — na outline of a General Thought of Models. Massachusetts: W.A. Benjamin.

(1991): Prédire n' est pas expliquer. Paris: Flammarion.

TROLL, C. (1997): A paisagem geográfica e sua investigação. Espaço e Cultura, Rio de Janeiro: UERJ-NEPEC, n. 4, jun., p.1-7.

TUAN, Y. F. (1974): Topophilia: a study of environmental attitudes, perceptions and vallues. Englewood Cliffs: Prentice Hall. 